\title{
THE IMPACT OF COVID-19 PANDEMIC ON THE FUTURE AIRPORT PASSENGER TERMINALS DESIGN
}

\author{
Igor Štimac ${ }^{1}$, Jelena Pivac ${ }^{2}$, Matija Bračić ${ }^{3}$, Miroslav Drljača ${ }^{4}$ \\ 1,2,3 Faculty of Transport and Traffic Sciences, University of Zagreb, Zagreb 10000, Croatia \\ ${ }_{1,4}$ Zagreb Airport Ltd., Rudolfa Fizira 1, 10410 Velika Gorica, Croatia \\ ${ }^{4}$ Department of Sustainable Mobility and Logistic, University North, Koprivnica, Croatia
}

Received 30 October 2020; accepted 8 December 2020

\begin{abstract}
The COVID-19 pandemic has had a huge influence on air transport. For the first time two thirds of the global aircraft fleet were grounded; airports recorded a decrease of $70-95 \%$ in passenger traffic, and many airlines went bankrupt. The negative trends of air traffic operations automatically decrease airport aeronautical and non-aeronautical revenues, bringing airports to the very bottom level of financial survival. However, after several months and after implementing the World Health Organization anti-COVID-19 measures, a small positive trend starts to be seen. The measures that need to be implemented have presented an additional problem for passenger terminal planning and design, especially if the introduction of new subsystems into the existing traffic flow, such as health control, is taken into account. Considering that current international recommendations from IATA ADRM are no longer valid, it is necessary to redefine the traffic flows inside the terminal and adjust the procedures of passengers and baggage handling to the new conditions of social distancing. Following that, ICAO Annex 9 recommendation that passengers need to be processed on departure traffic flow in 60 minutes went under question. New requirements for terminal space to keep passengers on safe distance, the implementation of new contactless technology for quick passenger processing, a thermal camera and health checkpoints, as well as other measures are now "new normal" for the airport business.
\end{abstract}

Keywords: COVID-19, world pandemic, airport, air travel, level of service, passenger terminal, anti-virus measures.

\section{Introduction}

Due to the coronavirus (COVID-19) pandemic, airports are trying to adapt to the "new normal" situation. Based on the current research on this topic, there are no reliable data on how long this pandemic will last, so it is hard to predict its final impact on airport business. The emergence and rapid spreading of the coronavirus have forced airlines to cancel many flights. Due to the World Health Organisation (WHO) measures recommended to prevent the spread of the COVID-19 pandemic and to avoid further virus transmission via travelers, air traffic has become one of the sectors most affected by the coronavirus. This paper refers to the future adjustment of the main airport passenger terminals components in the conditions of the COVID-19 pandemic. The COVID-19 pandemic impact on the air transport sector will be presented, and the

${ }^{1}$ Corresponding author: istimac@fpz.unizg.hr 
recommended measures which need to be applied in the passenger terminals will be listed. Considering the risk of the COVID-19 virus infection and the implementation of the WHO-recommended measures, it is necessary to redefine the capacity of passenger terminals, which presents a huge challenge for the airport planners and management. Each airport must have an individualized approach to dealing with the consequences, considering its business model, the existence of credit commitments, income, number of employees, and many other factors.

Given that, IATA's current recommendations about the terminal space, maximum queuing time, and occupancy defined in Airport Development Reference Manual (ADRM) are not applicable, thus a model with customized parameters including COVID-19 measures within the passenger terminal should be developed. To define an appropriate new approach for terminal capacity planning in the "new normal", it is necessary to analyse current available space, technology, and traffic flows. Based on that, it is crucial to see how WHO guidelines can be implemented into passenger terminal planning and design. Using this way of approach, the airport will maintain adequate service levels and prevent possible delays.

\section{Analysis of the Impact of COVID-19 Virus Pandemic on the Air Transport}

The aviation industry is one of the major sectors contributing to global economic growth. The emergence and the spread of coronavirus have had many negative consequences for the entire air sector. The COVID-19 virus pandemic led to restrictions on movement and travel bans, resulting in a sharp drop in air traffic. By the ICAO, an overall reduction of air passengers (both international and domestic) ranging from $52 \%$ to $59 \%$ in 2020 compared to 2019 (ICAO, 2020b). International Air Transport Association (IATA) reports a $54.7 \%$ decline in revenue passenger kilometres (RPKs, both international and domestic) in 2020 compared to 2019 (IATA, 2020b). Twothirds of the World's Passengers Jets are grounded due to COVID-19 Pandemic (Kotoky et al., 2020b). According to Bloomberg calculations, about 400.000 airline workers have been fired or told they might lose their jobs due to the situation with grounded aircraft caused by the coronavirus (Kotoky et al., 2020a). Airport Council International (ACI) announced that related to the passenger traffic, the European airports lose over 886 million passengers (ACI, 2020a). The same ACI estimated a loss of $57 \%$ or over $\$ 97$ billion airport revenues in 2020 compared to business as usual (ACI, $2020 \mathrm{~b}$ ). Eurocontrol announced that under its new "Current Status Scenario", the total number of flights expected in Europe in 2020 is anticipated to be 55\% lower than in 2019 (Eurocontrol, 2020b). Many airlines such as Chile's LATAM, Air Italy, Virgin Australia, British Flybe, Air Mauritius, Thai Airways, NokScoot, and South African Airways went bankrupt, and it remains to see which other airlines will not be able to overcome this crisis. Potential airline bankruptcies pose a major risk to the airports business. Airlines have been forced to reduce their capacity, which led to a sharp drop in revenues in the entire sector. When evaluating the importance of airports for the economic development of the regions, the impact of the COVID-19 virus is even greater. 


\subsection{Impact of COVID-19 on Airport Operations}

One of the airport business characteristics is the high cost of infrastructure maintenance. The sudden loss of traffic has led to a complete decline in aeronautical and nonaeronautical revenues that greatly influence airport business. The reduction in capacity of airlines greatly influences the aeronautical revenues that airports collect from airlines, such as aircraft landing fees, parking fees, centralized infrastructure fees, passenger fees, and ground handling fees. Following the above, as airline traffic decreased; there was a simultaneous decline in non-aeronautical revenues generated by restaurants, duty-free shops, or parking lots.

During the pandemic, most airports remained open for cargo operations, which was a relief for airport business and sustainability. However, there was a small decline in air cargo demand (10-15\%) as well. Since the airports are very affected by the pandemic, they also expect government support and financial assistance to ensure their survival while reducing costs to save revenue. Airports are forced to reduce variable costs wherever possible, such as closing part of the infrastructure (runways, parts of the passenger terminals), reducing staff, cutting salaries, and other measures. Historically, aviation has recovered relatively quickly from major crises such as 9/11 or SARS, within approximately half a year. Airport recovery will depend on many factors such as the pandemic's duration and intensity, the discovery of vaccines, and the speed of economic recovery after the pandemic.

As shown in Figure 1, the outbreak and spread of the COVID-19 virus is one of the largest global crises that has directly affected the global GDP growth. Airports are facing a crisis of this magnitude for the first time and have to solve problems on how to restart its operations with the airlines and guarantee safe and healthy passage through passenger terminal.

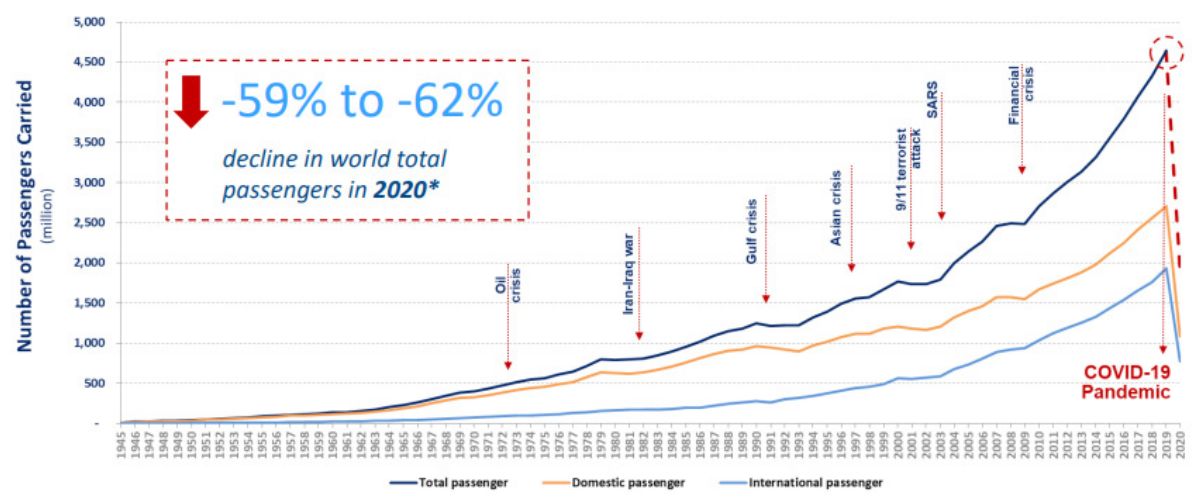

Fig. 1.

World Passenger Traffic Evolution 1945-2020

Source: (ICAO, 2020a) 
To adapt quickly to the new situation, IATA has issued guidelines, stating that each government should assist the aviation industry in financial support, tax relief, or loans. Such assistance helps airports to alleviate financial stress and to focus on a recovery strategy. Figure 2 shows the measures/initiatives that governments should take as soon as possible to achieve airport sustainability.
Currently, most airports have temporarily halted investment projects because the recovery phase is projected to take a long time. In this situation, modern technology such as self-service and contactless technology can help manage airport processes. These technologies can help optimize airport operations by reducing operating costs, improving the travel experience, and, most importantly, reducing the virus's spread.

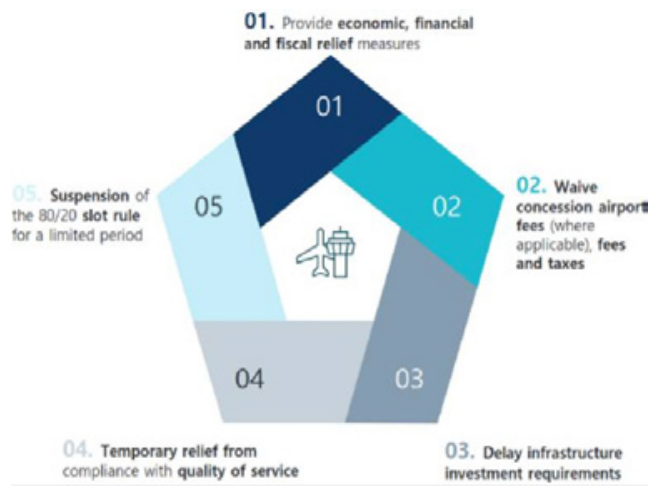

Fig. 2.

Five Measures/Initiatives from Government for Airport Operator

Source: $(A L G, 2020)$

\subsection{Current Situation and Recovery Forecast}

In early May 2020, air traffic slowly began to recover from the first wave's effects in March 2020. Given the current situation (and facing the second wave), it can be concluded that the next period will be extremely difficult for the airports. Due to the occurrence of the second wave of the pandemic in late August 2020, air traffic decreased again. The impact of coronavirus on the European air traffic for the past period and the change in the traffic situation when compared to 2019 are shown below (Eurocontrol, 2020a).
After reaching 69\% below the level of August 2019 in August 2020, passenger traffic began to decline from mid-August and reached 2.3 million passengers on 29 September ($72 \%$ compared to 2019 ). In total, since 1 st January 2020, Europe has experienced a loss of 1.3 billion passengers over 2019 (80\% less traffic). Furthermore, business aviation is recovering rapidly (only 10\% below the 2019 level), while cargo flights are $3 \%$ above the 2019 level.

In the Figure 3, according to the Eurocontrol report, several types of scenarios can be seen (actual, previous scenario and current 
scenario), which predict traffic until February 2021. For example, the previous scenario produced on April 242020 predicted a gradual recovery and remained very accurate from April to the end of August 2020. This prediction was correct (+/- 1\% each month). In September 2020, the previous scenario predicted a movement of traffic $40 \%$ below the level of 2019 , but in the real situation it was even 54\% lower. As previously mentioned, the reason for this is the emergence of the second wave of the pandemic, for which in April 2020 it was not known whether it would occur and if so, when exactly. For this reason, the previous scenario is somewhat more optimistic.

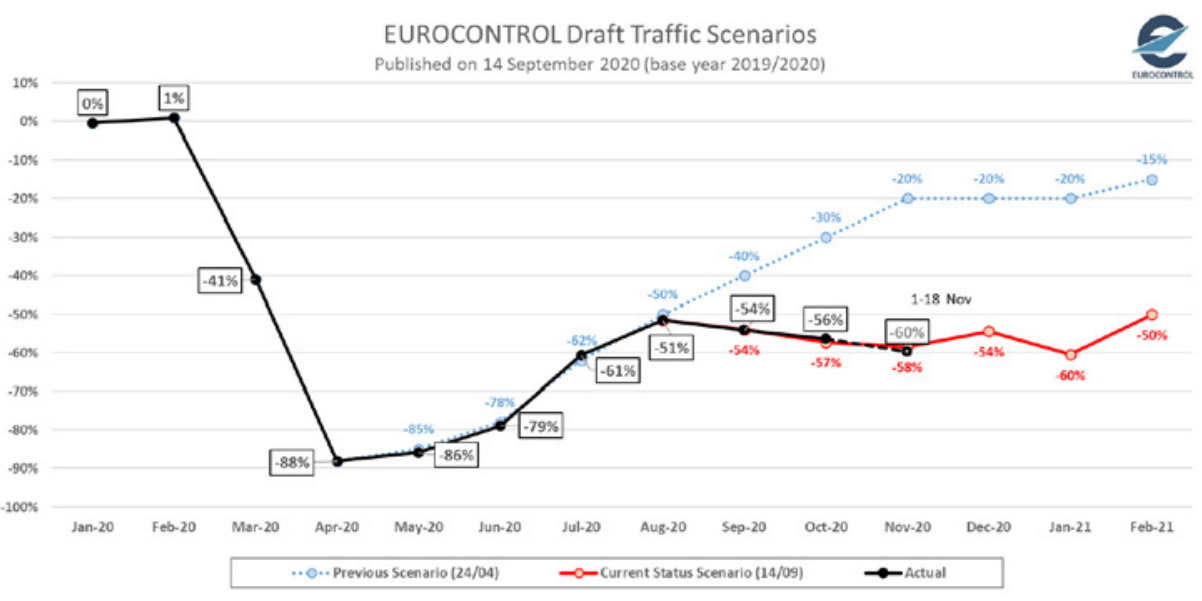

Fig. 3.

Draft Traffic Scenarios - 19 November 2020 (base year 2019/2020)

Source: (Eurocontrol, 2020b)

Due to the fact that after the summer 2020, COVID-19 has again halted the economy of many countries, especially in Europe where many countries have announced the "lockdown", it is now under question if this new Eurocontrol forecast is still too optimistic or the forecast line will decrease again. Eamonn Brennan, CEO of Eurocontrol, said, "We are going backward now, and it is really worrying for the entire industry". Despite the European Union Aviation Safety Agency (EASA) and the European Center for Disease Prevention and Control (ECDC) guidelines, there is a lack of coordination among countries on how to manage air travel (ALG, 2020). This uncoordinated approach leads to confusion and loss of passenger confidence. The introduction of common criteria for the quarantine measures and a better coordination between countries could improve the current scenarios. Although Eurocontrol is very cautious now, the ICAO, ACI, and IATA have announced that they expect traffic recovery in 2024 when the traffic will be on the same level as the one in 2019 (IATA, 2020a). 


\section{Methodology for Passenger Terminal Planning and Design Pre-COVID-19 and Post-COVID-19}

The designers of the airport passenger terminals must meet a wide range of different needs. Although the efficiency and flexibility of the passenger terminal remain a priority, designers must rethink the ways of designing and construction of the terminal and environment that support the highest level of service to passengers. All the above mentioned should be realized in order to build the adequate infrastructural and operational efficiency of the passenger terminal (TRB, 2010). In order to achieve an operationally efficient passenger terminal, various security requirements, procedures and activities from different stakeholders must be implemented in the correct way. To ensure that passenger terminal provides comfort to passengers and relatively fast boarding into the plane, it is necessary to design the passenger terminal space and its technological capacity properly. When dimensioning the main components of the terminal, it is recommended to leave the possibility of expanding them, without major modifications, due to the projected growth of traffic in the future. Figure 4 shows the steps in the traffic flows that every passenger must go through when departing and arriving at the passenger terminal (Figure 4). Available space per passenger, processing time and waiting time have been identified as key factors that influence the perception of the Level of Service by passengers. In general, the quality of service is assessed at peak times, i.e. at the time when the demand is the greatest. The optimal scenario for the airport has a uniform distribution of passengers during the day where there is no occurrence of longer queues and waiting.

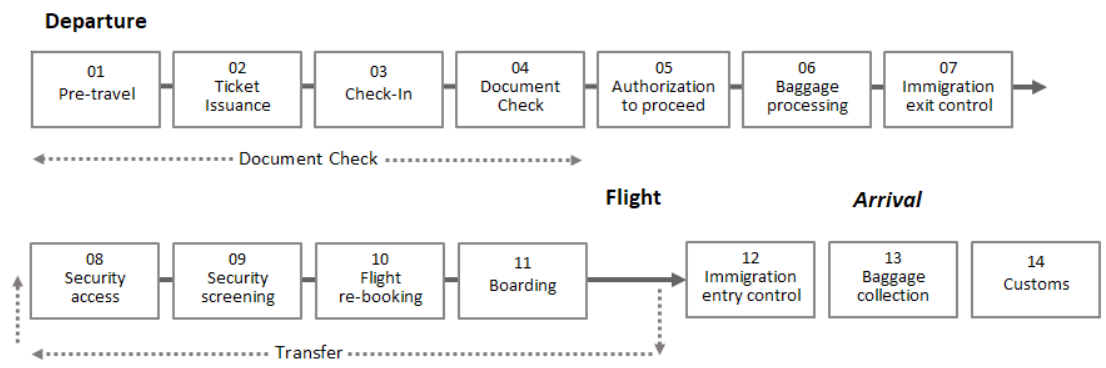

Fig. 4.

Process of Passengers and Baggage Handling

Source: (IATA, 2014)

\subsection{Pre-COVID 19 Passenger Terminal Design}

In the latest ADRM, IATA states that airports should regularly conduct infrastructure and operational capacity assessments to identify the source of any capacity problems in order to implement corrective actions. Globally, there are many airports that have huge problems with balancing positive passenger trends and lack of the airport capacity, resulting in frequent significant congestion 
and low service levels. When planning the airport passenger terminal, the two main elements profoundly influence its efficiency and profitability:

1. Terminal capacity optimization (space and time per subsystem);

2. Clearly defined traffic flows (its complexity depending on State rules).

Following the aviation industry, IATA develops guidelines for designing or evaluating service quality within terminals. Level of Service (LoS) Concept is initially developed in IATA's ADRM. During the years, IATA worked with ACI and other aviation consulting companies to upgrade its methodology so as to provide the aviation industry with a clear and available model for airport terminal planning and design. From 2004, IATA proposed a method where the Level of Service scale for passenger terminal ranked from $\mathrm{A} / \mathrm{B} / \mathrm{C} / \mathrm{D} / \mathrm{E} / \mathrm{F}$. In this scale, LoS "A" showed that terminal has overprovided space necessary for passengers and resulting in an inefficient and costly infrastructure to build, operate and maintain. This type of the terminal sub-systems results in substantial operational expenses for cleaning, air conditioning, heating, etc. which has a significant negative impact on the life-cycle cost analysis. On the other side, LoS "F" shows that the terminal has unacceptable LoS. Till the year 2014, IATA recommended LoS "C" as an appropriate Level of Service for designing new facilities or rating the operational performance of existing facilities. LoS "C" denotes the overall good service to passengers while balancing economic terminal sizing with passenger expectations. This methodology had shown certain weaknesses during the years, and in the year 2014, IATA published a new version of the ADRM (IATA, 2014), which includes a complete revision of the LoS Concept. From the previous methodology and LoS scale from "A-F", IATA defines 4 new levels as following: Over-Design, Optimum, Sub-Optimum, Under-Provided, where previously LoS "C" correspond new LoS Optimum. In line with those LoS, IATA defines four Key Performance Indicators (KPIs) on which a new LoS is calculated: Space, Maximum Queuing Time (MQT), Seating ratio, and Occupancy. Based on those measurements and quantitative results, IATA has defined a recommendation range for those 4 levels. The data on acceptable square meters, waiting times and occupancy rates per each subsystem are shown in Figure 5 (IATA, 2014).

At the global level, airports aim to achieve/ maintain the LoS Optimum with all its default parameters, otherwise the Level of Service is reduced. Waiting time, processing time and throughput of the main components of the terminal are just some of the requirements that must be considered to achieve a balanced LoS. The goal is to provide an optimal terminal space that will meet passenger requirements. Many airports use this concept to help them determine the requirements on the facilities for the projected throughput. If the facilities are designed to meet the demand in the peak hour, all subsystems will work in accordance with the optimal LoS, which is compatible with the throughput. As long as the airport does not reach the predicted level of activity, the facilities will function at a better LoS. 


\begin{tabular}{|c|c|c|c|c|c|c|c|c|c|c|c|c|c|}
\hline \multicolumn{2}{|c|}{ LoS Guidelines } & \multicolumn{3}{|c|}{$\begin{array}{l}\text { SPACE GUDDEUNES } \\
\text { [BQM/PAX] }\end{array}$} & \multicolumn{3}{|c|}{$\begin{array}{l}\text { Maximum Warting nime Guidetunts } \\
\text { tconomyryass } \\
\text { [minutes] }\end{array}$} & \multicolumn{3}{|c|}{$\begin{array}{l}\text { Maxamum Warming nime Guiotunes } \\
\text { Business Class / First Clas / Fast Track } \\
\text { [minutes] }\end{array}$} & \multicolumn{3}{|c|}{ OTHER GUIOLUNES \& REMARKS } \\
\hline & Los Parameter: & Over-Design & Optimum & Sub-optimum & Over-Design & Optimum & Sub-optimum & Over-Desien & Optimum & Sub-optimum & over-Design & Optimum & Sub-optimum \\
\hline \multicolumn{2}{|c|}{ Pubblic Departure Hall } & 22.3 & 20.23 & $<20$ & \multicolumn{3}{|c|}{$n / 2$} & \multicolumn{3}{|c|}{$n / 2$} & \multicolumn{3}{|c|}{$\begin{array}{l}\text { Optimum proportion of sested occupants } \\
15 \cdot 20 x^{*}\end{array}$} \\
\hline \multirow{4}{*}{ Chesk-in } & $\begin{array}{l}\text { Self-Service Kosti } \\
\text { (Borrting Pass / Mog Togging) }\end{array}$ & $>1.8$ & 1.3.1.8 & $<1.3$ & $<1$ & 1.2 & $>2$ & $<1$ & 1.2 & $>2$ & & & \\
\hline & $\begin{array}{l}\text { Bag Drop Desik } \\
\text { (quever wisth 1.4. 1.6m) }\end{array}$ & $>1.8$ & $1.3 \cdot 1.8$ & $<1.3$ & $<1$ & 1.5 & $>5$ & $<1$ & 1.3 & $>3$ & & & \\
\hline & \multirow{2}{*}{$\begin{array}{l}\text { Check-in Desk } \\
\text { (queve width: } 1.4 \cdot 1.6 \mathrm{~m})\end{array}$} & \multirow{2}{*}{$>1.8$} & \multirow{2}{*}{ 1.3.1.8 } & \multirow{2}{*}{$<1.3$} & \multirow{2}{*}{$<10$} & \multirow{2}{*}{$10 \cdot 20$} & \multirow{2}{*}{$>20$} & $<3$ & 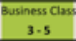 & $>5$ & & & \\
\hline & & & & & & & & $<1$ & $\begin{array}{c}\text { First Class } \\
1.3\end{array}$ & $>3$ & & & \\
\hline \multicolumn{2}{|c|}{\begin{tabular}{|l|} 
Sectrity Control \\
(queve wisth $1.2 \mathrm{~m}$ )
\end{tabular}} & $>1.2$ & 1.0.1.2 & $<10$ & <5 & $5 \cdot 10$ & $>10$ & $<1$ & $\begin{array}{c}\text { Fast Frack } \\
1-3\end{array}$ & 23 & & & \\
\hline \multicolumn{2}{|c|}{$\begin{array}{l}\text { Emigration Comprol (Outbound Passport Control) } \\
\text { (queveve widsh } 1.2 \mathrm{~m} \text { ) }\end{array}$} & $>1.2$ & $1.0-1.2$ & $<20$ & es & $5 \cdot 10$ & $>10$ & $<1$ & $\begin{array}{c}\text { Fast Track } \\
1.3\end{array}$ & 23 & & & \\
\hline \multirow{2}{*}{$\begin{array}{l}\text { Gate Holdrooms / } \\
\text { Departure } \\
\text { Lounges }\end{array}$} & Seating & $>1.7$ & 1.5-1.7. & <1.5 & \multirow{2}{*}{\multicolumn{3}{|c|}{ N/a }} & \multirow{2}{*}{\multicolumn{3}{|c|}{$\mathrm{N} / \mathrm{a}$}} & \multirow{2}{*}{\multicolumn{3}{|c|}{ 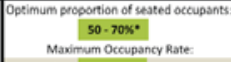 }} \\
\hline & Standing & $>1.2$ & $1.0 \cdot 1.2$ & $<10$ & & & & & & & & & $\begin{array}{l}\text { nykate: } \\
>70 \mathrm{x} \\
\text { nats }\end{array}$ \\
\hline \multicolumn{2}{|c|}{ 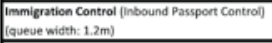 } & $>1.2$ & 1.0.1.2 & $<10$ & $<5$ & $5 \cdot 10$ & $>10$ & $<1$ & $\begin{array}{c}\text { Fast Track } \\
1.5\end{array}$ & 25 & & & \\
\hline \multirow{2}{*}{ Bascase Recliaim } & Nazrow Body Aircratt & $>1.7$ & 1.5.1.7 & $<1.5$ & $<0$ & $0 / 15$ & $>15$ & \multirow{2}{*}{$<0$} & \multirow{2}{*}{$0 /$ is } & \multirow{2}{*}{$>15$} & \multirow{2}{*}{\multicolumn{3}{|c|}{ 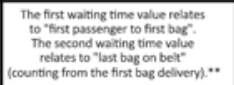 }} \\
\hline & Wise Body Aircerath & $>1.7$ & 1.5-1.7 & $<1.5$ & $<0$ & $0 / 25$ & $>25$ & & & & & & \\
\hline \multicolumn{2}{|l|}{ Customs control } & $>1.8$ & 1.3.1.8 & $<2.3$ & $<1$ & 1.5 & $>5$ & $<1$ & 1.5 & 25 & \multicolumn{3}{|c|}{$\begin{array}{l}\text { Waiting times refere to a procedure } \\
\text { when } 1005 \text { of the passengers } \\
\text { are being checied by Customs }\end{array}$} \\
\hline \multicolumn{2}{|l|}{ Public Arrival Hall } & 22.3 & 20.23 & $<20$ & \multicolumn{3}{|c|}{$\mathrm{N} / \mathrm{a}$} & \multicolumn{3}{|c|}{$n / a$} & Optimum props & $\begin{array}{l}\text { oportion of se } \\
15-20 x^{*}\end{array}$ & med occupants: \\
\hline
\end{tabular}

Fig. 5.

Space and Maximum Queuing Time (MQT) Recommendation Source: (IATA, 2014)

Proper sizing of passenger terminal components requires a combination of research, calculation, modeling (simulation) and, primarily, experience. It is essential to have a complete understanding of the operational parameters necessary for passengers and aircraft handling. Each of the functions that support passengers' movement from the landside towards the aircraft requires special attention. This functional understanding is especially complex due to the continued development of the airline industry. Improvement, process innovation, and contingencies affect many key functional areas of today's passenger terminals.

\subsection{Post-COVID 19 Passenger Terminal Design}

The pandemic of COVID-19 has influenced air traffic rapidly, challenging airport infrastructure and operational procedures. Due to the lack of time, airports management have had two different approaches to the COVID-19 pandemic:

1. Permanent action - activities that need to be done "overnight" in line with all WHO recommendations;

2. Short-to medium-term action modification at passenger terminal infrastructure and implementation of new contactless technology in subsystems over entire traffic flows.

The first "overnight" actions that airports undertook were related to implementing the "soft" recommendation from the WHO to minimize the risk of SARS-CoV-2 transmission. European Commission, EASA, and ECDC have jointly developed detailed technical, operational guidelines for the aviation sector. Consequently, the airports have adopted the recommended measures to preserve health and safety of their passengers and staff. Several prompt proactive and protective measures have been 
introduced to enable the safe and effective passenger screening process at checkpoints in a COVID environment. These measures are:

- Social Distance - related to the WHO recommendations, airports have introduced the rule of maintaining a social distance of 1-2 meters in all the areas in the terminal. This measure mainly applies to places where people are waiting in lines or lingering for a longer period of time (e.g. checkins, security check, passport control, baggage retrieval, waiting rooms, cafes, restaurants, shops, toilets, elevators). Social distancing is mostly maintained with stickers on the floor, walls, or benches that instruct passengers where to stand or sit (Figure 6);

- Disinfection and Cleaning - cleaning involves the physical removal of dirt and impurities, while disinfection destroys organisms at the microbiological level. The emphasis is placed on the areas exposed to a frequent contact by passengers, such as check-in counters and baggage, boarding, passport control, doors, and trolleys;

- Using Personal Protective Equipment - depending on State policy, it is recommended or mandatory to wear personal protective equipment at the airport terminal and during the flight. It involves wearing protective masks or visors that also reduce the possibility of droplet transmission of the pathogen;

- Information Boards for Passengers and Stuff - putting up visible notices (posters, displays, floor stickers) at the entrance and exit of passenger terminals, as well as in the terminal. The staff must take care to monitor compliance with the prescribed measures;

- Physical Barriers - physical barriers are mostly found on the counters in each subsystem in traffic flow to avoid transmission of COVID-19 from passengers to airport stuff. These physical barriers are mostly made from a transparent material, such as plexiglass (Figure 6);

- Ventilation System - one of the important measures is ventilation to ensure a frequent change of air in the passenger terminal;

- Measurement of Body Temperature - this measure is important, especially at the passenger terminal entrance, to see if some airport users have COVID-19. This activity is done with a hand thermometer, although some airports also implement the Thermal Imaging Camera;

- Disinfectant Booths - several of airports (e.g. Hong Kong) also implement fullbody disinfectant booths CLeanTech that sanitize passengers' clothing and bodies in 40 seconds (Fox et al., 2020).

In addition to the previously mentioned measures, passengers are constantly encouraged to use as much as possible the Internet and mobile applications for their registration on the flight in order to minimize contacts. During the passengers' stay at the passenger terminal, it is necessary to minimize the interaction with the ground staff.

Related to the short-to-medium-term action, from the airport terminal planner perspective, all the recommendations and KPI's published in IATA ADRM due to this COVID-19 "New Normal" are no longer useful. Primarily, they refer to area, maximum queuing time and seating ratio. Due to the passenger social distance, an area for passengers waiting in the queue for Check-In, Security or any other subsystem 
are no longer adequate, resulting in the passenger line going outside the dedicated queueing area and consequently, affecting other subsystems. In addition, when implementing the preventive measures, it is necessary to consider the real risk factors, such as family members or individuals travelling together as part of the same household. In this case, it is not necessary to require social distancing between them. Due to the lack of synchronization of terminal subsystems capacity caused by the new antiCOVID-19 measures, the MQT can also be prolonged, directly influencing the passenger Level of Service.

The third important element is the seating ratio and the occupancy of chairs in a waiting room. Due to the recommended distance,
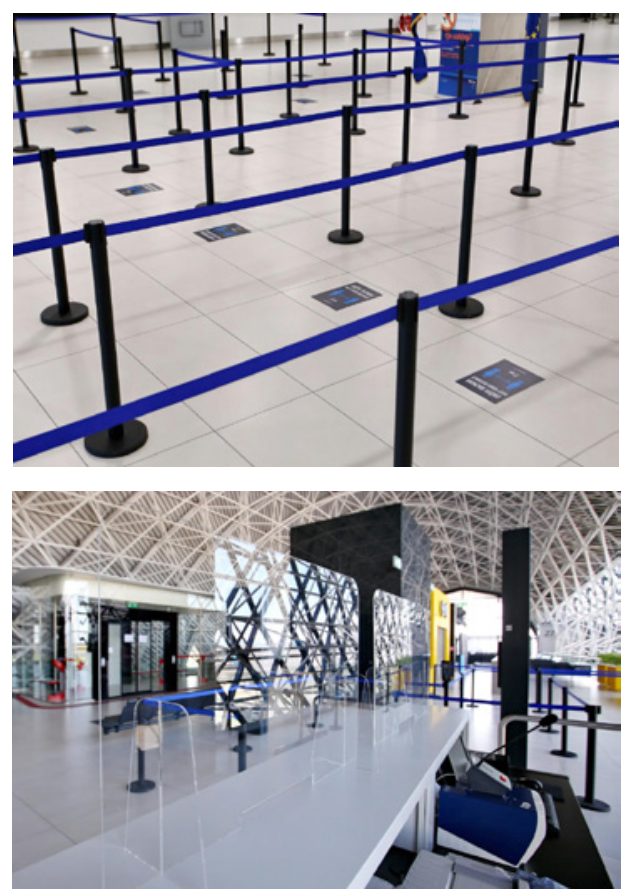

Fig. 6.

Anti COVID-19 Measures

Source: (MZLZ \& Škof, 2020.) it can be stated that waiting rooms have limitations now. The total capacity of seats is reduced by approx. $50 \%$. The only solution for this is to increase the area of the waiting rooms, which causes certain infrastructure problems. However, many airports do not have the ability and financial resources to modify their terminal in a short-medium time.

Furthermore, the challenge for the airport planners is that they will need to add an additional important subsystem - health control, which is introduced with the appearance of the COVID-19 virus. This additional checkpoint will challenge airport terminal planners, especially in cases where the passenger terminal already lacks space and capacity.
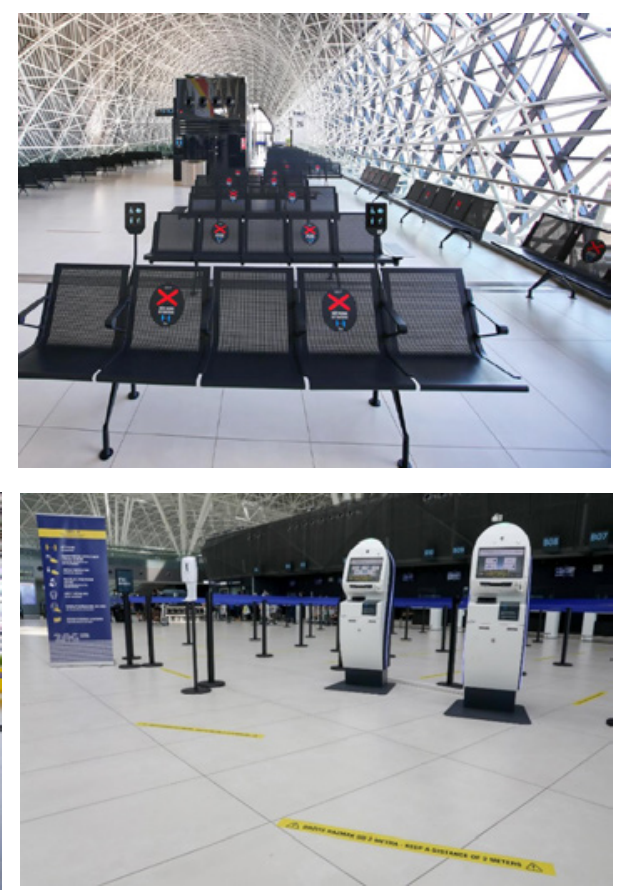
In the future, airports will need to conduct new capacity assessments while aware of COVID-19 risks. It is necessary to make new estimates of the number of passengers, as well as to analyse and understand the nature of the queues and movements of people in these areas, what equipment they use and the like. The question is how to deal with a larger number of passengers while respecting the recommendation of social distancing when additional space is not easily available (either it is expensive or impossible to ensure). Therefore, it is necessary to reconsider how the airport can handle the number of passengers as in the period before COVID-19, adhering to the recommended physical distance of $1.5 \mathrm{~m}$, especially in some situations such as delayed departure flights, flight cancellations, etc., for which reasons the flow of passengers is slowed down and the concentration of passengers in a limited space increase. These recommended measures will be regularly updated in line with the evolution of the pandemic. Airports must constantly follow the recommendations of the relevant organizations and apply them in their operational processes.

The German company ARC made a simulation that clearly showed how passenger terminal subsystems looked before and during the COVID-19 pandemic (Figure 7). The simulation was made for the following subsystems: Entrance to the Terminal, Check-in and Gate (TRB, 2010).
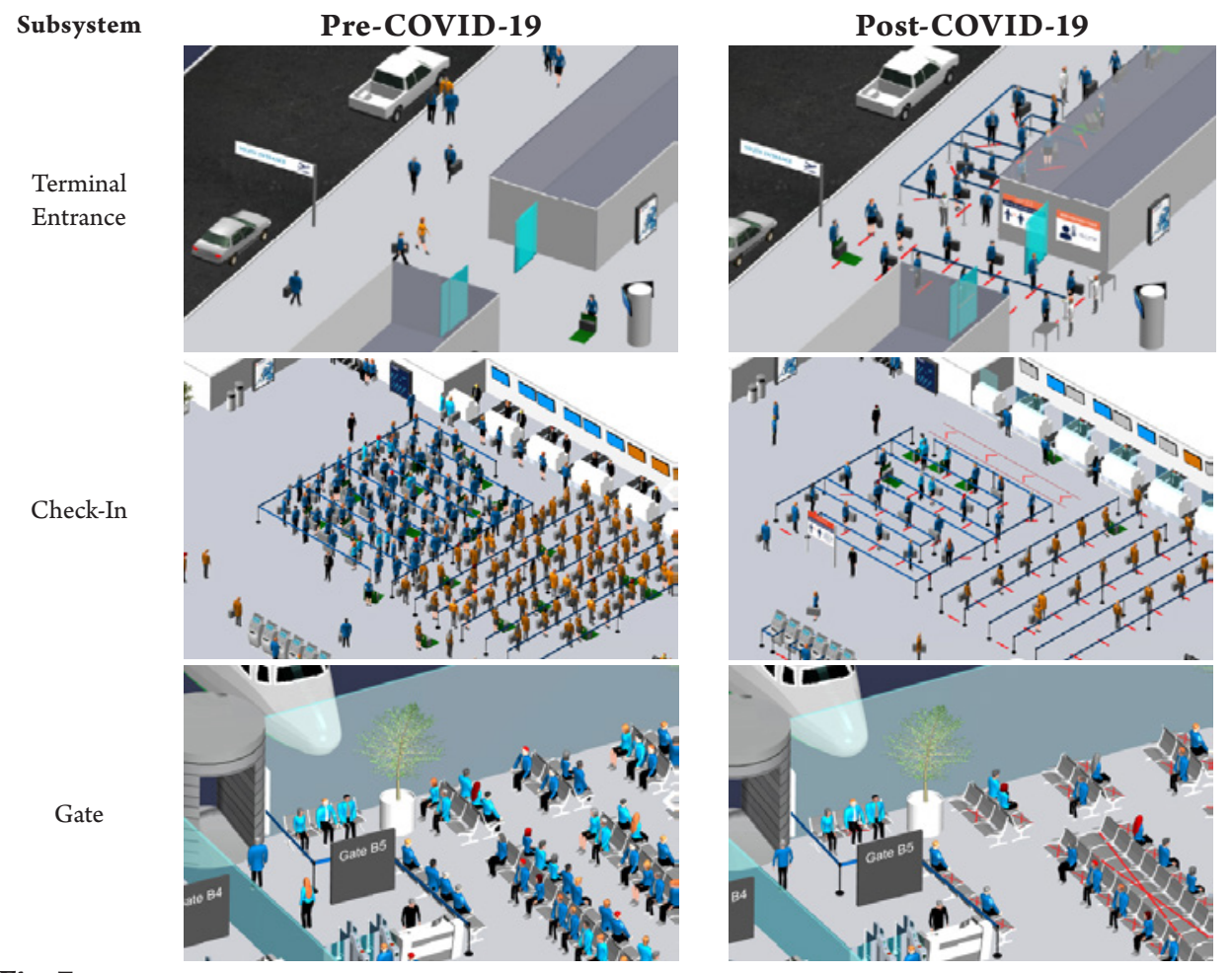

Fig. 7.

Pre-COVID-19 vs Post COVID-19 Simulation (Simulation Developed by ARC on CAST Terminal) Source: (ARC, 2020) 
The infrastructure and technology solutions that are implemented in the COVID-19 situation are the following:

a. If there is a possibility to increase the queuing area in any subsystem, it is highly recommended to do so;

b. If there is not enough space in front of a subsystem, the recommendation is to increase the number of units in the subsystem to increase its capacity, and the result will be a decrease in queuing time and number of passengers in front of the subsystem. What needs to be considered is that, although the number of units is increased, the airport management needs to ensure additional staff who will work on these new units;

c. If there are also limitations on the number of units and (space) area, then a solution can be found in the flight schedule modification (if possible). This is the final solution, but it can avoid all aircraft delays in a certain flight hour.

\section{Conclusion}

The Covid-19 pandemic with a sudden loss of traffic and revenue resulted in an existential threat to airports and the aviation industry. Given the enormous negative impact of the COVID-19 virus on the airport business, it will take a long time for the situation to return to normal. It is expected that the economic crisis following the pandemic will lead to a lower demand for air transportation. The industry experts predict a much slower recovery than any other crises such as $9 / 11$ or SARS, where ICAO, IATA, ACI, and Eurocontrol agreed that results from 2019 would be achieved in 2025. Currently, most airports are implementing their business continuity plans regarding service maintenance and core operations during this crisis. At the same time, the airport operators are forced to revise their usual business processes. Operational processes and their optimization will be the main priority of airports in the upcoming period. Although airports have had a prompt reaction to prevent transmission of COVID-19 with simplified solutions, it is expected that they will invest more in new technology and infrastructure in the future. From the point of view of terminal planning perspective and technology, the airports will need to invest in fully contactless technology in each terminal subsystem to avoid future virus transmission, as probably there will be similar viruses such as COVID-19. That technology is invented, so the next step is to implement it. In addition to that, new subsystems will be added to current traffic flows. One important subsystem of the passenger terminal that will be added is health control, which has been introduced with the appearance of the COVID-19 virus. This additional checkpoint will challenge airport terminal planners, especially those where the passenger terminal already lacks space and capacity. Finally, such new subsystems will also influence the current ICAO recommendation, where 60 minutes was the maximum time for the entire departure passenger and 45 minutes for arrival processes. These times will also be prolonged in the future. It can be said that there are technological solutions that can be added at the passenger terminals in order to fight against COVID-19 or any other virus. This implies certain changes and innovations in the process of passengers and baggage handling, which includes revision and change of individual operating procedures and additional staff training. However, the time for reaction and implementation of such solutions will be challenging for airport managers and planners. 


\section{References}

ARC. 2020. Airport Challenges in Reacting to Covid-19. Airport Research Center. Available from Internet: $<$ https://arc.de/airport-challenges-in-reacting-tocovid-19/>.

ACI. 2020a. Latest traffic data shows disastrous COVID-19 impact on airport industry. Airports Council International. Available from Internet: <https://www. aci-europe.org/press-release/270-latest-traffic-datashows-disastrous-covid-19-impact-on-airport-industry. html>.

ACI. 2020b. Predicted global impact of COVID-19 on airport industry escalates. Airports Council International. Available from Internet: < https://aci. aero/news/2020/05/05/predicted-global-impact-ofcovid-19-on-airport-industry-escalates/>.

ALG. 2020. Aviation Covid-19 Briefing, Latin American \& Caribbean Airports, ALG Transport and Infrastructure. Available from Internet: <https:// algnewsletter.com/wp-content/uploads/2020/04/ Aviation-COVID-19-LAC-by-ALG.pdf $>$.

Dwyer, M. 2020. Eurocontrol Issues New Draft Traffic Scenarios, Available from Internet: <https:// flyinginireland.com/2020/09/eurocontrol-issues-newdraft-traffic-scenarios/>.

Eurocontrol. 2020a. COVID-19 Impact on European Air Traffic, Eurocontrol Comprehensive Assessment. Available from Internet: <https://www.eurocontrol.int/ publication/eurocontrol-comprehensive-assessmentcovid-19s-impact-european-air-traffic $>$.

Eurocontrol. 2020b. Draft Traffic Scenarios for September 2020 - February 2021. Impact of State restrictions, uncoordinated approach and uncertainty over COVID-19, Brussels.
Fox, A. 2020. Hong Kong's airport is rolling out full-body disinfectant booths that sanitize passengers' clothing and bodies in 40 seconds. Available from Internet: $<$ https://www.businessinsider.com/hong-kong-airportfull-body-disinfectant-booths-coronavirus-2020-5>.

IATA. 2014. Airport Development Reference Manual (ADRM), 10th edition, International Air Transport Association, Montréal, Canada.

IATA. 2020a. Recovery Delayed as International Travel Remains Locked Down, International Air Transport Association, Montreal, Canada. Available from Internet: $<$ https://www.iata.org/en/pressroom/pr/2020-07$28-02 />$.

IATA. 2020b. Air passenger demand comes to a standstill amidst lockdowns, International Air Transport Association, Montreal, Canada. Available from Internet: <https://www.iata.org/en/iata-repository/publications/ economic-reports/air-passenger-monthly-analysis--apr-20202/>.

ICAO. 2020a. Effects of Novel Coronavirus (COVID-19) on Civil Aviation: Economic Impact Analysis, International Civil Aviation Organization. Available from Internet:<https://www.icao.int/sustainability/ Documents/COVID-19/ICAO_Coronavirus_Econ_ Impact.pdf $>$.

ICAO. 2020b. State of Global Air Transport and ICAO Forecasts for Effective Planning, International Civil Aviation Organization, Economic Development, Workshop presentation, Air Transport Bureau.

Kotoky, A.; Modi, M.; Turner, M. 2020a. Jobs Are Being Wiped Out at Airlines, And There's Worse to Come, Bloomberg. Available from Internet: <https://www. bloombergquint.com/business/400-000-jobs-lost-atairlines-during-coronavirus-pandemic $>$. 
Kotoky, A.; Stringer, D.; Saxena, R. 2020b. TwoThirds of the World's Passengers Jets Are Grounded Amid COVID-19 Pandemic. Available from Internet: URL: <https://time.com/5823395/grounded-planescoronavirus-storage/ $>$.

MZLZ; Škof, J. 2020. Pictures of interior of Franjo Tuđman passenger terminal during COVID-19, Zagreb International Airport Jsc, MZLZ archive, Zagreb, Croatia.

TRB. 2010. Transportation Research Board: ACRP Report 25. Airport Passenger Terminal Planning and Design Volume 1: Guidebook, Airport Cooperative Research Program, Washington, United States of America. 